\title{
Elastic and optical properties of $\mathrm{Ge}_{x} \mathrm{Se}_{2} \mathrm{Sb}_{1-x}(0.0 \leq x \leq 1.0)$ glasses
}

\author{
K A ALY ${ }^{1,2, *}$, N AFIFY ${ }^{3}$, Y B SADDEEK ${ }^{2}$ and A M ABOUSEHLY ${ }^{2}$ \\ ${ }^{1}$ Physics Department, Faculty of Science and Arts Khulais, Jeddah University, P.O. Box 80200, 21589 Khulais, \\ Saudi Arabia \\ ${ }^{2}$ Physics Department, Faculty of Science, Al-Azhr University (Assiut Branch), Assiut 71524, Egypt \\ ${ }^{3}$ Physics Department, Faculty of Science, Assiut University, Assiut 71516, Egypt
}

MS received 9 March 2015; accepted 28 October 2015

\begin{abstract}
The present study deals with the effect of composition on the elastic and optical properties of $\mathrm{Ge}_{x} \mathrm{Se}_{2} \mathrm{Sb}_{1-x}(0.0 \leq x \leq 1.0)$ glasses. The various elastic moduli of these glasses such as Young's modulus $(Y)$ and the bulk modulus $(B)$ along with the micro-hardness $(H)$, Poisson's ratio $(\sigma)$ and Debye temperature $\left(T_{\mathrm{D}}\right)$ were obtained from the values of the longitudinal $\left(v_{1}\right)$ and shear $\left(v_{\mathrm{s}}\right)$ ultrasonic velocities. On the basis of measurements of the transmittance and reflectance spectra in the wavelength range of 0.4-2.5 $\mu \mathrm{m}$ the optical constants such as the film thickness $(t)$, the refractive index $(n)$ and the optical band gap $\left(E_{\mathrm{g}}\right)$ were investigated with high accuracy. The optically determined bulk modulus of these glasses was in good agreement with that elastically investigated. The obtained results were discussed in terms of the changes in the glass density, electronegativity and electronic polarizability with the variation in antimony content.
\end{abstract}

Keywords. Chalcogenides; optical parameters; elastic moduli; electronic polarizability.

\section{Introduction}

Ternary glassy alloys have wide band gap $\left(E_{\mathrm{g}} \approx 1-3 \mathrm{eV}\right)$ that are produced by the combination of IV-VI groups have attracted intensive studies owing to their great potentials for a various applications. These applications include advanced IR optical fibre [1], photostructural, optical recording [1-3] and acousto-optic devices [4,5]. Furthermore, due to their favourable elastic and interfacing properties they are often preferred to their crystalline counter-parts with similar properties. In the past decades, many authors have worked on different glass compositions like Se-Ge-In, $\mathrm{Sb}-\mathrm{Ge}-\mathrm{Se}, \mathrm{Ge}-$ As-Se and Se-Ge-Bi [6-15]. Rabinal et al [16] have studied the chemical ordering in $\mathrm{Se}_{80-x} \mathrm{Ge}_{20} \mathrm{In}_{x}$ glasses. The composition effect on the optical properties of $\mathrm{Sb}-\mathrm{Ge}-\mathrm{Se}$ and $\mathrm{Ge}_{10} \mathrm{As}_{x} \mathrm{Se}_{90-x}$ films has been studied [6]. Sb-Ge-Se glasses have been preferred in the fabrication of optical devices because of their high transparency in the 8-12 $\mu \mathrm{m}$ region and their good elastic, thermal and chemical properties $[6,8,17,18]$. Moreover, many extensive studies have been carried out to modify the mathematical formulation describing the transmittance and reflectance for different glasses [17-20]. Therefore, it is important to characterize these glasses through studying the composition effect of their optical parameters (refractive index, extinction coefficient and the optical band gaps) on antimony.

In the present study, the elastic and optical properties of different compositions of $\mathrm{Ge}_{x} \mathrm{Se}_{2} \mathrm{Sb}_{1-x}$ (with $x=0.0,0.2$,

\footnotetext{
*Author for correspondence (kaali5@Uj.edu.sa, Kamalaly2001@gmail.com)
}

$0.4,0.68,0.8$ and 1.0) were investigated. The ultrasonic velocities (longitudinal $v_{1}$ and shear $v_{\mathrm{s}}$ ) have been measured through the pulse-echo technique in order to investigate the elastic moduli and Debye temperature $\left(T_{\mathrm{D}}\right)$. Films with sufficiently high thickness $(\sim 0.7 \mu \mathrm{m})$ help us to avoid the effect of thickness of film on the optical constants and also successful application of Swanepoel's analysis [19] in the range of transparency can be achieved. This procedure leads to accurate determination of the refractive index and film thickness. On the basis of the measured transmittance and reflectance spectra in the region of strong absorption, the absorption coefficient has been calculated.

\section{Experimental}

The elemental components (Ge, Sb, and Se with $5 \mathrm{~N}$ purity, from Koch Light Co.) in appropriate proportions were introduced into a quartz ampoule with $15 \mathrm{~mm}$ in diameter under a vacuum of $10^{-4}$ Torr. The ampoule contents were melted in an electric furnace at $1150^{\circ} \mathrm{C}$ for $24 \mathrm{~h}$. Then the ampoule was cooled to $850^{\circ} \mathrm{C}$ and quenched in hot water $\left(90^{\circ} \mathrm{C}\right)$ in order to prevent any cracking or shattering of the cylindrical sample during further processing. Care was taken to preserve the vertical status of the ampoule during the quenching operation. Then the ampoule was annealed for $1 \mathrm{~h}$ at about five degrees higher than the glass transition temperature $\left(T_{\mathrm{g}}\right)$. After that, the ampoule was brought to room temperature by slowly cooling just before breaking open the ampoule. An ice bath for $15 \mathrm{~min}$ is necessary for facilitating retrieval of the glass from the ampoule. 
Glasses in the form of circular discs with a diameter of $1.2 \mathrm{~cm}$ and length of $0.6 \mathrm{~cm}$ were obtained. Two parallel sides were polished for the measurements of ultrasonic velocities. Non-parallelism of the two opposite side faces was less than $0.01 \mathrm{~mm}$.

On the basis of pulse-echo technique both of the longitudinal $\left(v_{1}\right)$ and shear $\left(v_{\mathrm{s}}\right)$ ultrasonic velocities in $\mathrm{m} \mathrm{s}^{-1}$ were measured through the measurements of time interval between the initiation and the receipt of the pulse appearing on the screen of flaw detector (USM3-Kraütkramer) by standard electronic circuit (Philips PM 3055 Oscilloscope). A bonding material called Nonaq Stopcock Grease was applied to $\mathrm{x}$-cut and $\mathrm{y}$-cut transducers (KARL DEUTSCH) operated at a fundamental frequency $4 \mathrm{MHz}$. The detected echoes were displayed on an oscilloscope, so that the first half-cycle of the radio frequency in each echo may be observed. If there is a slight distortion in the first half-cycle of each echo, due to any part of the transducer bond sample combination, the time between the first half-cycle of each represents the exact round trip time in the sample. At low range of mega-hertz frequencies, the system can be considered very effective. The velocity was investigated by dividing the round trip distance by the elapsed time. The random errors were \pm 15 and $\pm 20 \mathrm{~ms}^{-1}$ for measuring $v_{\mathrm{l}}$ and $v_{\mathrm{s}}$, respectively.

The density $\rho$ (in $\mathrm{kg} \mathrm{m}^{-3}$ ) for $\mathrm{Ge}_{x} \mathrm{Se}_{2} \mathrm{Sb}_{1-x}$ glasses was measured to the third decimal $\left( \pm 20 \mathrm{~kg} \mathrm{~m}^{-3}\right)$ by the displacement method using toluene as an immersion liquid. Based on the obtained values of the density the molar volume $V_{\mathrm{m}}$ was $\left(V_{\mathrm{m}}=M / \rho\right)$ where $M$ is the molecular weight of the glass.

Different compositions of $\mathrm{Ge}_{x} \mathrm{Se}_{2} \mathrm{Sb}_{1-x}$ films have been deposited onto well-cleaned glass substrates using the vacuum evaporation technique. The deposition chamber was kept for $24 \mathrm{~h}$ for achieving thermodynamic equilibrium. Both the rate of the film deposition $\left(0.5 \mathrm{~nm} \mathrm{~s}^{-1}\right)$ and thickness was controlled by DTM-100 quartz crystal monitor. Like this low rate of deposition produces a film composition as the same starting bulk materials [20]. PANalytical's X'Pert PRO X-ray diffractometer $\left(2 \theta=10-70^{\circ}\right)$ has been used to characterize $\mathrm{Ge}_{x} \mathrm{Se}_{2} \mathrm{Sb}_{1-x}$ thin films. The compositions of evaporated films were checked at different spots (size $\approx 2 \mu \mathrm{m}$ ) using EMPA (JEOL $8600 \mathrm{MX}$ ). The composition of $\mathrm{Ge}_{x} \mathrm{Se}_{2} \mathrm{Sb}_{1-x}$ films $(1.5 \mathrm{~cm} \times 1.25 \mathrm{~cm})$ was found to be uniform within an accuracy greater than $\pm 1.0 \%$. The transmission and reflectance spectra at room temperature $(300 \mathrm{~K})$ for $\mathrm{Ge}_{x} \mathrm{Se}_{2} \mathrm{Sb}_{1-x}$ films were measured in the spectra range 400$2600 \mathrm{~nm}$ using double-beam UV-Vis-NIR (Perkin Elmer Lambda 750).

\section{Results and discussions}

Figure 1 shows the X-ray diffraction (XRD) patterns of the as-prepared $\mathrm{Ge}_{x} \mathrm{Se}_{2} \mathrm{Sb}_{1-x}$ (with $x=0.0,0.2,0.4,0.68,0.8$ and 1.0) chalcogenide glasses. The general feature of these patterns confirms the amorphous nature of the as-prepared films. The elemental compositions of $\mathrm{Ge}_{x} \mathrm{Se}_{2} \mathrm{Sb}_{1-x}$ glasses are given in table 1 referred to the nominal composition

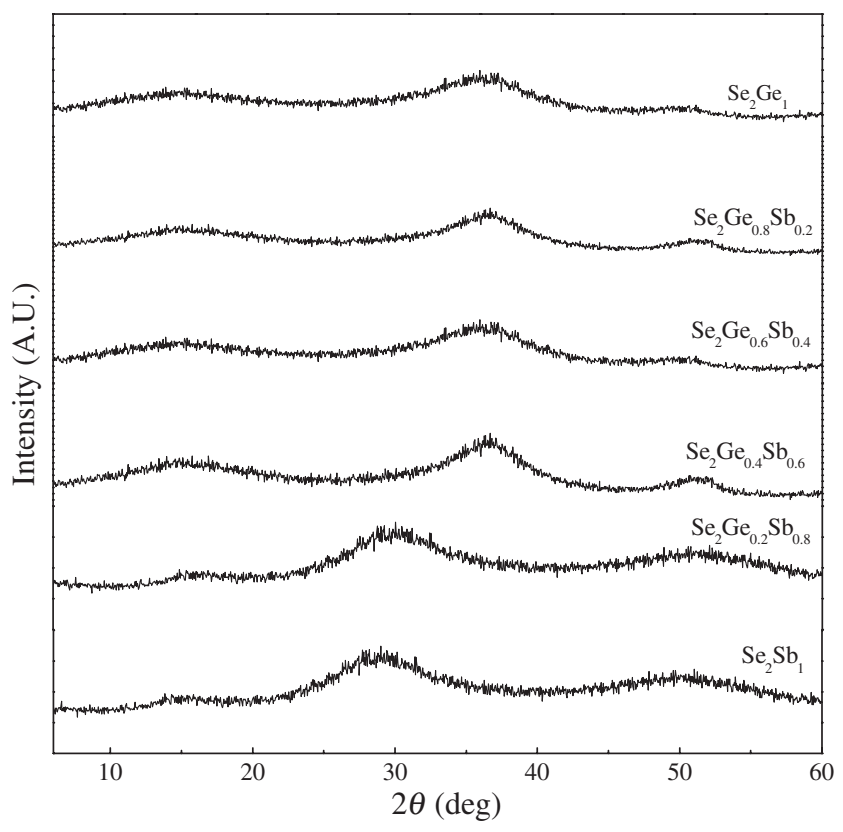

Figure 1. XRD patterns for $\mathrm{Ge}_{x} \mathrm{Se}_{2} \mathrm{Sb}_{1-x}$ with $(0.0 \leq x \leq 1)$ glasses.

(the starting mixture), where the weight losses were found to be less than $\pm 1 \%$.

Variations of density $(\rho)$ and molar volume $\left(V_{\mathrm{m}}\right)$ with the antimony concentrations in $\mathrm{Ge}_{x} \mathrm{Se}_{2} \mathrm{Sb}_{1-x}$ glasses are listed in table 2. Substituting Ge by $\mathrm{Sb}$ atoms leads to the observed increase in glass density and molar volume. This increase in density and molar volume with the increase in Sb content is expected, since its atomic weight, density and atomic radius of $\mathrm{Sb}$ are higher than that of $\mathrm{Ge}$. The increase in the molar volume expanded the amorphous network and consequently both longitudinal and shear velocities decreased with the increase in $\mathrm{Sb}$ concentration in these glasses.

\subsection{Elastic properties}

The elastic moduli of amorphous material can be determined by using two parameters namely, the longitudinal modulus $\left(L=\rho v_{1}^{2}\right)$ and the shear modulus $\left(S=\rho v_{\mathrm{s}}^{2}\right)$. By applying the equations derived by Rajendran et al [21] the elastic moduli can be determined in terms of the two moduli and their values are listed in table 2.

The ratio between lateral and longitudinal strain produced when tensile force is applied is an important parameter which is called as Poisson's ratio $(\sigma)$. As the ultrasonic velocities decreased, Poisson's ratio increased with the increase in the chalcogen content that can be ascribed to transformation of the glass structure from an essentially network to a chain-like form [22]. Here although the Se concentration has a constant value but one can found that the excess of chalcogen $\mathrm{Se}-\mathrm{Se}$ bond are increased with the increase in antimony concentrations (table 2). Moreover, Poisson's ratio can be correlated with the dimensionality of glass network [23]. The increase in Poisson's ratio may be attributed to the loosely bonded 
Table 1. EDX results and film thickness for $\mathrm{Ge}_{x} \mathrm{Se}_{2} \mathrm{Sb}_{1-x}$ (with $x=0.0,0.2,0.4,0.68,0.8$ and 1.0) thin films.

\begin{tabular}{lrccc}
\hline & \multicolumn{4}{c}{ EDX results at } \\
\cline { 2 - 4 } Composition & \multicolumn{1}{c}{$\mathrm{Se} \pm$} & $\mathrm{Ge}$ & $\mathrm{Sb}$ & \multirow{2}{*}{$d(\mu \mathrm{m})$} \\
\hline $\mathrm{Se}_{2} \mathrm{Ge}_{1}$ & $66.4 \pm 2.2$ & $33.6 \pm 2.2$ & 0.00 & $0.662 \pm 0.002$ \\
$\mathrm{Se}_{2} \mathrm{Ge}_{0.8} \mathrm{Sb}_{0.2}$ & $66.63 \pm 2.5$ & $26.46 \pm 1.9$ & $6.91 \pm 0.6$ & $0.670 \pm 0.003$ \\
$\mathrm{Se}_{2} \mathrm{Ge}_{0.6} \mathrm{Sb}_{0.4}$ & $66.71 \pm 2.4$ & $19.84 \pm 1.2$ & $13.45 \pm 1.03$ & $0.632 \pm 0.002$ \\
$\mathrm{Se}_{2} \mathrm{Ge}_{0.4} \mathrm{Sb}_{0.6}$ & $66.667 \pm 2.6$ & $12.313 \pm 0.9$ & $21.02 \pm 1.5$ & $0.655 \pm 0.004$ \\
$\mathrm{Se}_{2} \mathrm{Ge}_{0.2} \mathrm{Sb}_{0.8}$ & $66.667 \pm 2.3$ & $6.307 \pm 0.51$ & $27.026 \pm 2.4$ & $0.684 \pm 0.003$ \\
$\mathrm{Se}_{2} \mathrm{Sb}_{1}$ & $67 \pm 2.2$ & 0.00 & $33 \pm 1.86$ & $0.692 \pm 0.002$ \\
\hline
\end{tabular}

Table 2. Glass density $(\rho)$, molar volume $\left(V_{\mathrm{m}}\right)$, ultrasonic velocities (longitudinal $V_{\mathrm{l}}$ and shear $V_{\mathrm{s}}$ ), elastic moduli (longitudinal modulus $(L)$, shear modulus $(S)$, bulk modulus $(B)$, microhardness $(H)$ and Young's modulus $(Y))$, Poisson's ratio $(\sigma)$, Debye temperature $\left(T_{\mathrm{D}}\right)$ and the excess of $\mathrm{Se}-\mathrm{Se}$ bonds for ternary $\mathrm{Se}_{2} \mathrm{Ge}_{1-x} \mathrm{Sb}_{x}(0 \leq x \leq 1)$ chalcogenide glasses.

\begin{tabular}{|c|c|c|c|c|c|c|c|c|c|c|c|c|}
\hline Composition & $\begin{array}{c}\rho \pm 20 \\
\left(\mathrm{~kg} \mathrm{~m}^{-3}\right)\end{array}$ & $\begin{array}{l}V_{\mathrm{m}} \times 10^{-6} \\
\left(\mathrm{~m}^{3} \mathrm{~mol}^{-1}\right)\end{array}$ & $\begin{array}{l}V_{1} \pm 15 \\
\left(\mathrm{~m} \mathrm{~s}^{-1}\right)\end{array}$ & $\begin{array}{l}V_{\mathrm{s}} \pm 20 \\
\left(\mathrm{~m} \mathrm{~s}^{-1}\right)\end{array}$ & $\begin{array}{c}L \pm 0.15 \\
(\mathrm{GPa})\end{array}$ & $\begin{array}{c}S \pm 0.2 \\
(\mathrm{GPa})\end{array}$ & $\begin{array}{c}B \pm 0.17 \\
(\mathrm{GPa})\end{array}$ & $\begin{array}{c}H \pm 0.1 \\
(\mathrm{GPa})\end{array}$ & $\begin{array}{c}Y \pm 0.18 \\
(\mathrm{GPa})\end{array}$ & $\sigma \pm 0.002$ & $\begin{array}{c}T_{\mathrm{D}} \pm 2 \\
(\mathrm{~K})\end{array}$ & $\begin{array}{c}\text { Excess } \\
\text { of Se-Se }\end{array}$ \\
\hline $\mathrm{Se}_{2} \mathrm{Ge}_{1}$ & 4437 & 17.62 & 2835 & 1635 & 35.66 & 11.86 & 19.85 & 1.97 & 29.67 & 0.251 & 285.95 & 0 \\
\hline $\mathrm{Se}_{2} \mathrm{Ge}_{0.8} \mathrm{Sb}_{0.2}$ & 4518 & 17.97 & 2650 & 1520 & 31.73 & 10.44 & 17.81 & 1.71 & 26.20 & 0.255 & 264.23 & 3 \\
\hline $\mathrm{Se}_{2} \mathrm{Ge}_{0.6} \mathrm{Sb}_{0.4}$ & 4598 & 18.33 & 2452 & 1417 & 27.65 & 9.23 & 15.34 & 1.54 & 23.07 & 0.249 & 244.54 & 6 \\
\hline $\mathrm{Se}_{2} \mathrm{Ge}_{0.4} \mathrm{Sb}_{0.6}$ & 4676 & 18.89 & 2240 & 1292 & 23.46 & 7.81 & 13.06 & 1.30 & 19.53 & 0.251 & 220.76 & 11 \\
\hline $\mathrm{Se}_{2} \mathrm{Ge}_{0.2} \mathrm{Sb}_{0.8}$ & 4760 & 18.99 & 2095 & 1220 & 20.89 & 7.09 & 11.45 & 1.21 & 17.62 & 0.243 & 207.94 & 13 \\
\hline $\mathrm{Se}_{2} \mathrm{Sb}_{1}$ & 4840 & 19.26 & 1820 & 1050 & 16.03 & 5.34 & 8.92 & 0.89 & 13.35 & 0.251 & 178.26 & 16 \\
\hline
\end{tabular}

network linkages which leads to the formation of disconnected structural units and in turn gives rise to lower dimensional connectivity. By increasing $\mathrm{Sb}$ content the ordering degree of the amorphous species $\left(\mathrm{Se}_{2} \mathrm{Sb}_{3}\right)$ increased with slight ordering in the periodicity at the expense of the amorphous matrix that increases the values of the density and decreases the elastic moduli [24].

Microhardness expressed the required stress to eliminate the glass free volume [25]. The calculated values of $H$ are found to decrease with the increase in the concentrations of $\mathrm{Sb}$ (table 2) that can be ascribed to the formation of large precipitates on the expense of others. This result also confirmed the softening (ductility) character as $\mathrm{Sb}$ increased in $\mathrm{Ge}_{x} \mathrm{Se}_{2} \mathrm{Sb}_{1-x}$ glasses [26]. Furthermore, the structure transformations from a three dimensional to a chain-like structure leads to a decrease in the values of microhardness [27]. The observed decrease in the hardness confirmed that there are a structural contribution with the addition of generally accepted interpretation based on the continuous change of the outer electron concentration per atom [28].

The Debye temperature $\left(T_{\mathrm{D}}\right)$ is an important parameter of glass and can be determined based on elastic constant data, since $T_{\mathrm{D}}$ is directly proportional to the average sound velocity $\left(V_{\mathrm{a}}=\left(V_{1}^{-3}+2 V_{\mathrm{s}}^{-3}\right)^{-1 / 3}\right)$ by this equation [29]:

$$
T_{\mathrm{D}}=\frac{h}{k_{b}}\left(\frac{3 q N_{\mathrm{A}}}{4 \pi V_{\mathrm{m}}}\right)^{1 / 3} V_{\mathrm{a}},
$$

where $h, k_{b}$ and $N_{\mathrm{A}}$ with the usual meaning in quantum mechanics, and $q$ the number of atoms. The values of $T_{\mathrm{D}}$ for $\mathrm{Ge}_{x} \mathrm{Se}_{2} \mathrm{Sb}_{1-x}$ glasses are listed in table 2. The observed decrease in the values of bulk modulus is due to the change in the value of the average stretching force constant of different bonds [30]. According to the chemical bond approach [31-33] the strongest Ge-Se bonds (49.44 $\mathrm{kal} \mathrm{mol}^{-1}$ [32]) are expected to occur first followed by $\mathrm{Sb}-\mathrm{Se}$ bonds (43.98 $\mathrm{kal} \mathrm{mol}^{-1}$ [32]). After these bonds are formed there are excess of $\mathrm{Se}$ valences that leading to the formation of homopolar Se-Se bonds (44.04 kal mol ${ }^{-1}$ [32]). The excess of homopolar $\mathrm{Sb}-\mathrm{Sb}$ bonds are found to increases with the increase of Sb content (table 2). The heteronuclear bonds like $\mathrm{Ge}-\mathrm{Se}$ and $\mathrm{Sb}-\mathrm{Se}$ are calculated based on the homonuclear bonds and the electronegativities of the constituent atoms as detailed in references $[33,34]$. Therefore, increasing the Sb content softened the acoustic mode of the amorphous alloy which decreased all of the elastic parameters. It was worth mentioned that the obtained values of the elastic moduli $\mathrm{Ge}_{x} \mathrm{Se}_{2} \mathrm{Sb}_{1-x}$ glasses are well agreed with those previously determined by the authors [34-36].

\subsection{Optical properties}

Analysis of the transmission and reflection spectra of the $\mathrm{Ge}_{x} \mathrm{Se}_{2} \mathrm{Sb}_{1-x}$ films demonstrates that antimony doping of $\mathrm{Ge}_{1} \mathrm{Se}_{2}$ shifted the optical absorption edge of the films towards the lower photon energies (figure 2). The inset of this figure showed the measured film reflectance spectra for $\mathrm{Ge}_{1} \mathrm{Se}_{2}$ and $\mathrm{Se}_{2} \mathrm{Sb}_{1}$ films.

The refractive index $n(\lambda)$ for $\mathrm{Ge}_{x} \mathrm{Se}_{2} \mathrm{Sb}_{1-x}$ thin films has been calculated according to previously detailed works 


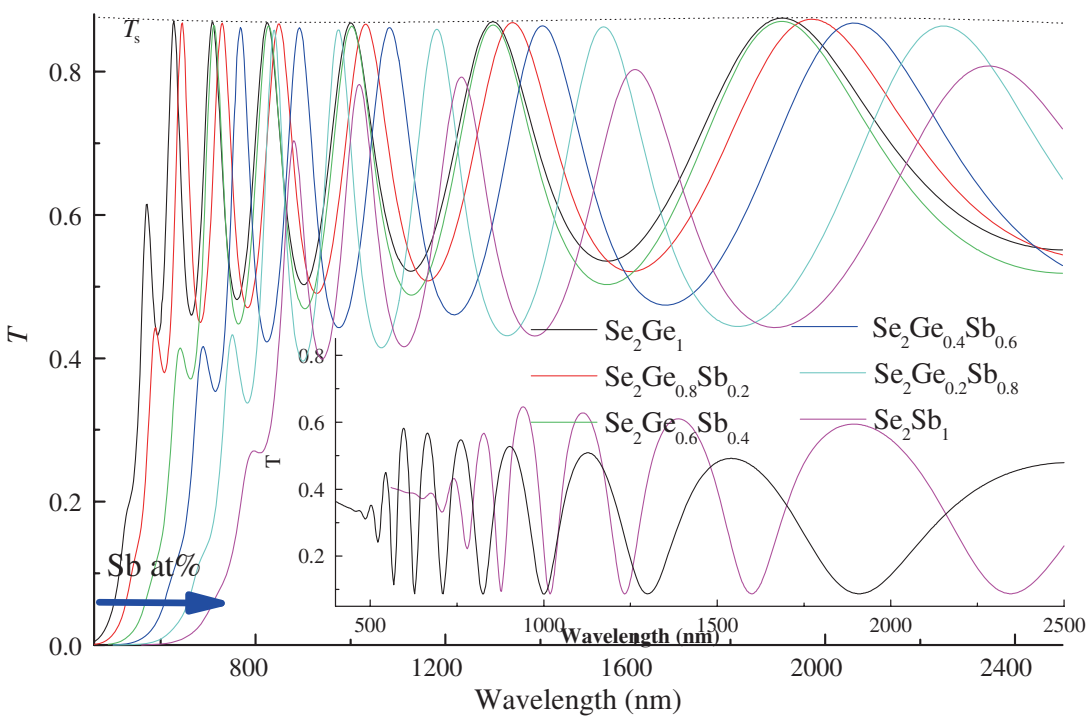

Figure 2. Transmittance spectra for $\mathrm{Ge}_{x} \mathrm{Se}_{2} \mathrm{Sb}_{1-x}$ thin films with $(0.0 \leq x \leq 1)$. The inset of this figure shows reflectance spectra for the first sample $(x=0)$ and the last sample $(x=1)$.

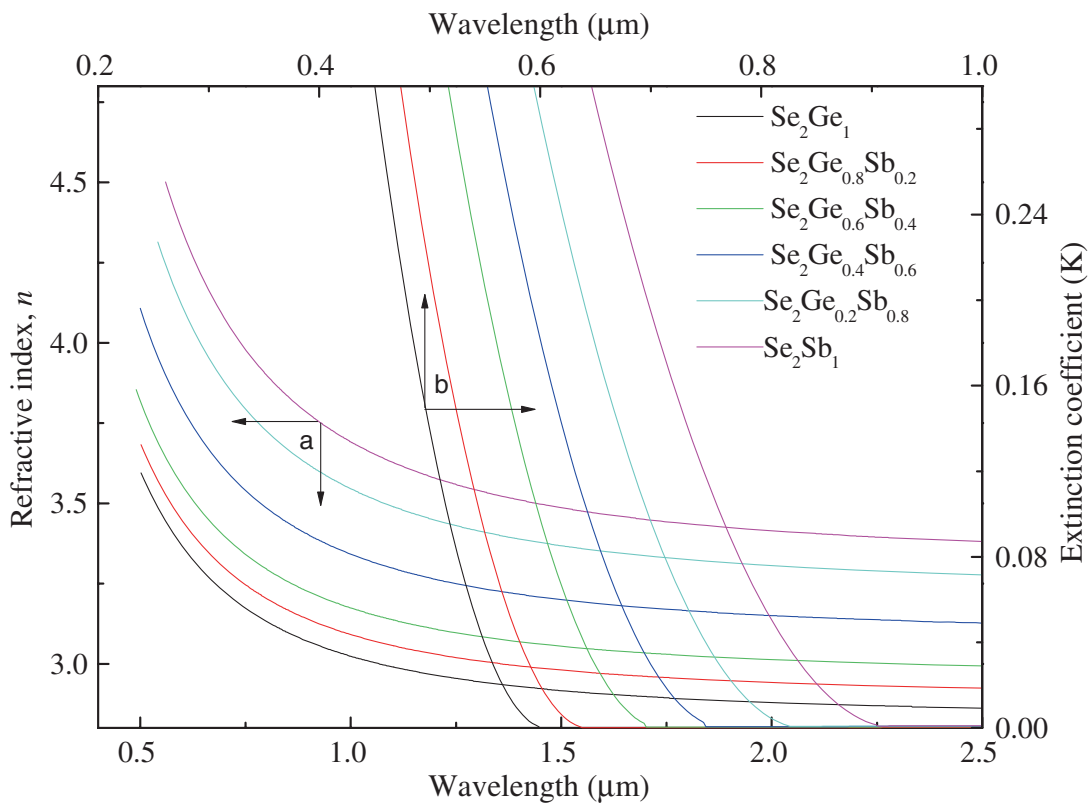

Figure 3. (a) Index of refraction $(n)$ and (b) the absorption coefficient or extinction coefficient, $(k)$ as a function of the wavelength for $\mathrm{Ge}_{x} \mathrm{Se}_{2} \mathrm{Sb}_{1-x}$ thin films with $(0.0 \leq$ $x \leq 1)$.

[37,38]. Figure 3a shows the variations in the values of the refractive index with composition. The refractive index increased with the increase in the concentrations of antimony. Like this manner would be expected due to the replacement germanium with smallest atomic radii $(1.23 \AA)$ by the largest antimony atoms with atomic radii $1.45 \AA$. Thus, the addition of $\mathrm{Sb}$ at the expense of Ge leads to the increase in the electronic polarizability and therefore the refractive index [39].
The electronic polarizability for $\mathrm{Ge}_{x} \mathrm{Se}_{2} \mathrm{Sb}_{1-x}$ films can be calculated from the Clausius-Mossotti relationship

$$
\propto_{0}=0.395\left(n^{2}-1 / n^{2}+1\right) V_{\mathrm{m}} .
$$

The calculated values of $\alpha_{0}$ were plotted as a function of $\lambda$ and are as shown in figure 4 . Furthermore the values of $\alpha_{0}$ has been calculated by substituting the $n_{\mathrm{g}}$ values into equation (2) where $n_{\mathrm{g}}$ is the refractive index at cutoff wavelength 


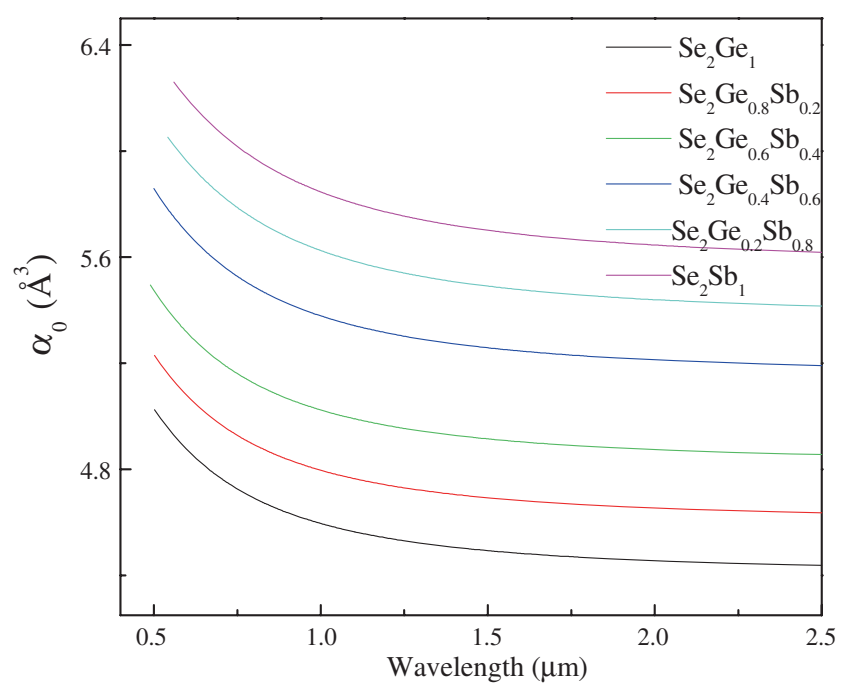

Figure 4. Variation in electronic polarizability $\alpha_{\mathrm{o}}$ with the wavelength for $\mathrm{Ge}_{x} \mathrm{Se}_{2} \mathrm{Sb}_{1-x}$ thin films with $(0.0 \leq x \leq 1)$.

$\left(\lambda=h c / E_{\mathrm{g}}\right)$. It was noted that the electronic polarizability increase as well as the $\mathrm{Sb}$ content is increases. In the range of transparency where the refractive index can be fitted in accordance to the Wemple-DiDomenico (WDD) dispersion relation $[40,41]$

$$
n^{2}(h v)-1=E_{0} E_{\mathrm{d}} /\left(E_{0}^{2}-(h v)^{2}\right),
$$

where $E_{0}$ is the single oscillator energy that is the average optical band gap (WDD gap), $E_{\mathrm{d}}$ the dispersion energy which is a measure of the average strength of inter-band transition. Both the $E_{0}$ and $E_{\mathrm{d}}$ values can be easily determined using the slope and the intercept of the plot of refractive index parameter $\left(n^{2}(h v)-1\right)^{-1} v s$. the squared of photon energy $(h v)$ as shown in figure 5. Furthermore, when the photon energy tends to zero $(v \rightarrow 0)$ equation (3) can be rewritten as $n(0)=\sqrt{1+E_{\mathrm{d}} / E_{0}}$. The deduced values of $E_{0}, E_{\mathrm{d}}$ and $n(0)$ are listed in table 3. It is well known that, the single oscillator energy $E_{0}$ is corresponded to the average separation between the valence and conduction bands; therefore, it is related to the average molar bond energy of the different bonds presented in the material. Thus, the observed decrease in the value of the $E_{0}$ for $\mathrm{Ge}_{x} \mathrm{Se}_{2} \mathrm{Sb}_{1-x}$ films is ascribed to the increase of the lowest bond energy $\mathrm{Sb}-\mathrm{Sb}(1.3 \mathrm{eV})$ and $\mathrm{Sb}-\mathrm{Se}(1.89 \mathrm{eV})$ bonds at the expense of $\mathrm{Ge}-\mathrm{Se}(2.13 \mathrm{eV})$. Therefore, the formation of $\mathrm{Sb}-\mathrm{Sb}$ and $\mathrm{Sb}-\mathrm{Se}$ bonds reduce the optical band gap in $\mathrm{Ge}_{x} \mathrm{Se}_{2} \mathrm{Sb}_{1-x}$ films with the increase in $\mathrm{Sb}$ concentrations. The changes in $E_{\mathrm{d}}$ values with compositions gives more understand for refractive index manner.

As demonstrated in table 3, the value of $E_{\mathrm{d}}$ increased with the increase in the Antimony concentration. This increase in $E_{\mathrm{d}}$ values can be attributed mainly to the change in the ionicities of Se-Se homopolar bonds and extra introduced $\mathrm{Sb}$ atoms. Thus, the values of $n(0)$ is increased with the increase in the $\mathrm{Sb}$ concentrations that can be ascribed to the large

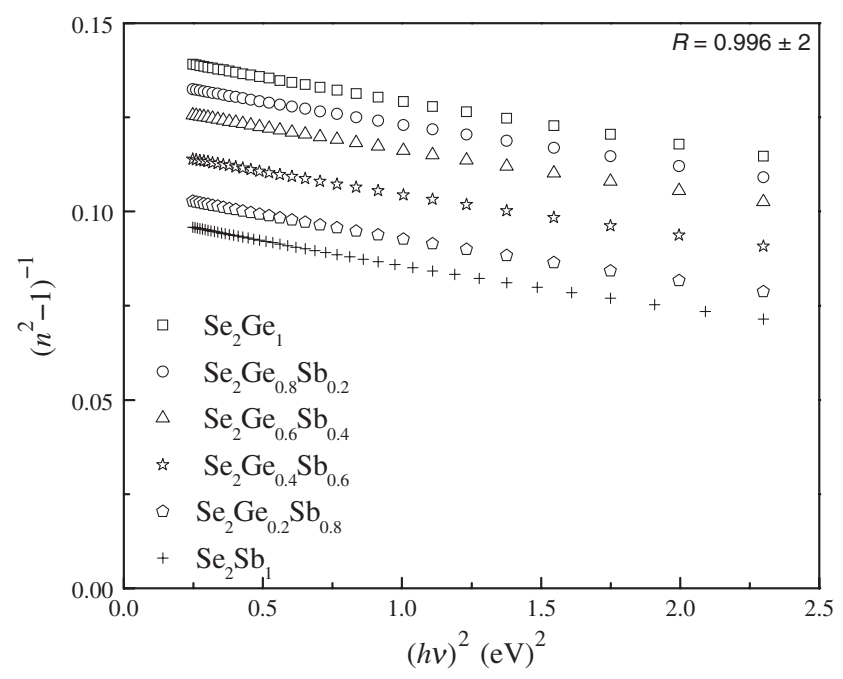

Figure 5. Refractive index parameter $\left(n^{2}-1\right)^{-1}$ against the photoenergy $(h v)$ for $\mathrm{Ge}_{x} \mathrm{Se}_{2} \mathrm{Sb}_{1-x}$ thin films with $(0.0 \leq x \leq 1)$.

atomic polarizability of $\mathrm{Sb}$ atoms in comparison with that of Ge atoms.

The absorption coefficient $\alpha$ was evaluated from the reflection and transmission spectra, $R(\lambda)$ and $T(\lambda)$, with allowance for reflection in the layer

$$
\alpha=t^{-1} \ln \left(\left(1-R_{1}\right)\left(1-R_{2}\right)\left(1-R_{3}\right) / T\right),
$$

where $R_{1}$ is the substrate-air reflectance, $R_{1}=\left(n_{1}-1 /\right.$ $\left.n_{1}+1\right)^{2}, R_{2}$ the film-air reflectance, $R_{2}=(n-1 / n+1)^{2}$, $R_{3}$ the substrate-film reflectance, $R_{3}=\left(n_{1}-n / n_{1}+n\right)^{2}, t$ the specimen thickness, $T$ the transmittance of the film, $n_{1}$ the refractive index of the substrate and $n$ the film refractive index. Moreover, the extinction coefficient $(k)$ can be calculated through the formula, $k=\alpha \lambda / 4 \pi$. The changes in the values of the extinction coefficient with the Sb content are shown in figure $3 \mathrm{~b}$. On the bais of Tauc's method (figure 6), the optical band gap $\left(E_{\mathrm{g}}\right)$ of $\mathrm{Ge}_{x} \mathrm{Se}_{2} \mathrm{Sb}_{1-x}$ films has been estimated. Sb doping reduced the optical band gap and therefore, the spectral broadening of the exponential tail of the absorption edge (Urbach's tail slope, $\Gamma$ as shown in figure 7) can be interpreted as evidence that $\mathrm{Sb}$ doping increased the degree of structural disorder in the GeSe films.

The total optical electronegativity difference, $\Delta \chi$, for ternary and complex glassy system can be estimated by substituting the value of the band gap, $E_{\mathrm{g}}$, into the Dufy relation [42] in the form of

$$
\Delta \chi=0.2688 E_{\mathrm{g}} .
$$

Substituting $B, \Delta \chi$ and $E_{\mathrm{g}}$, respectively, in ClausiusMossotti relation gives the electronic polarizability $\left(\alpha_{0}\right.$ in $\AA^{3}$ ) in terms of the bulk modulus as [43]

$$
\begin{aligned}
\propto_{0}= & 0.395\left((5.563-0.033 B)^{2}-1\right) / \\
& \left((5.563-0.033 B)^{2}+2\right) V_{\mathrm{m}},
\end{aligned}
$$


Table 3. Band gap energy $\left(E_{\mathrm{g}}\right)$, optical electronegativity $(\Delta \chi)$, normal dispersion parameters (single oscillator energy $\left(E_{0}\right)$, oscillator strength $\left(E_{\mathrm{d}}\right)$, and the static index of refraction $\left.(n(h v=0))\right)$, theoretical or optical calculated of bulk modulus $\left(B_{\mathrm{th}}\right)$, and the electronic polarizability, $\alpha\left(\AA^{3}\right)$.

\begin{tabular}{|c|c|c|c|c|c|c|c|c|c|c|}
\hline \multirow[b]{2}{*}{ Composition } & \multirow[b]{2}{*}{$\begin{array}{c}E_{\mathrm{g}} \pm 0.01 \\
(\mathrm{eV})\end{array}$} & \multirow[b]{2}{*}{$\begin{array}{c}\Delta \chi \\
\text { equation }(5)\end{array}$} & \multirow[b]{2}{*}{$\begin{array}{c}\Gamma \pm 0.001 \\
(\mathrm{eV})\end{array}$} & \multirow[b]{2}{*}{$\begin{array}{c}E_{0} \pm 0.02 \\
(\mathrm{eV})\end{array}$} & \multirow[b]{2}{*}{$\begin{array}{c}E_{\mathrm{d}} \pm 0.2 \\
(\mathrm{eV})\end{array}$} & \multirow[b]{2}{*}{$n(0) \pm 0.03$} & \multirow[b]{2}{*}{$\begin{array}{l}B_{\text {th }} \text { equation } \\
\text { (6) }(\mathrm{GPa})\end{array}$} & \multicolumn{3}{|c|}{ Electronic polarizability, $\alpha\left(\AA^{3}\right)$} \\
\hline & & & & & & & & $\begin{array}{c}\text { Equation } \\
\text { (2) }\end{array}$ & $\begin{array}{c}\text { Equation } \\
\text { (6) }\end{array}$ & $\begin{array}{c}\text { Equation } \\
\text { (8) }\end{array}$ \\
\hline $\mathrm{Se}_{2} \mathrm{Ge}_{1}$ & 2.05 & 0.551 & 0.028 & 4.20 & 23.68 & 2.836 & 19.78 & 5.385 & 6.159 & 5.154 \\
\hline $\mathrm{Se}_{2} \mathrm{Ge}_{0.8} \mathrm{Sb}_{0.2}$ & 1.93 & 0.519 & 0.035 & 3.90 & 24.77 & 2.897 & 17.97 & 5.512 & 6.302 & 5.311 \\
\hline $\mathrm{Se}_{2} \mathrm{Ge}_{0.6} \mathrm{Sb}_{0.4}$ & 1.75 & 0.470 & 0.041 & 3.55 & 25.59 & 2.965 & 15.22 & 5.650 & 6.452 & 5.509 \\
\hline $\mathrm{Se}_{2} \mathrm{Ge}_{0.4} \mathrm{Sb}_{0.6}$ & 1.62 & 0.435 & 0.048 & 3.21 & 26.72 & 3.094 & 13.23 & 5.911 & 6.673 & 5.751 \\
\hline $\mathrm{Se}_{2} \mathrm{Ge}_{0.2} \mathrm{Sb}_{0.8}$ & 1.48 & 0.398 & 0.053 & 2.90 & 27.48 & 3.237 & 11.13 & 6.054 & 6.721 & 5.863 \\
\hline $\mathrm{Se}_{2} \mathrm{Sb}_{1}$ & 1.35 & 0.362 & 0.057 & 2.77 & 28.05 & 3.336 & 9.09 & 6.198 & 6.841 & 6.037 \\
\hline
\end{tabular}

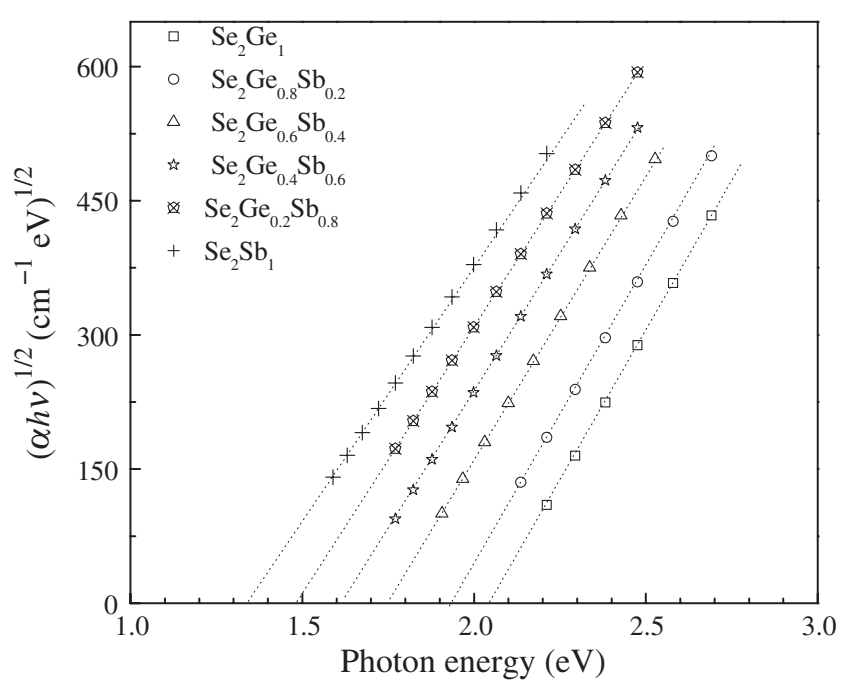

Figure 6. Parameter $(\alpha h v)^{1 / 2}$ of the absorption coefficient $v s$. photon energy for $\mathrm{Ge}_{x} \mathrm{Se}_{2} \mathrm{Sb}_{1-x}$ thin films with $(0.0 \leq x \leq 1)$.

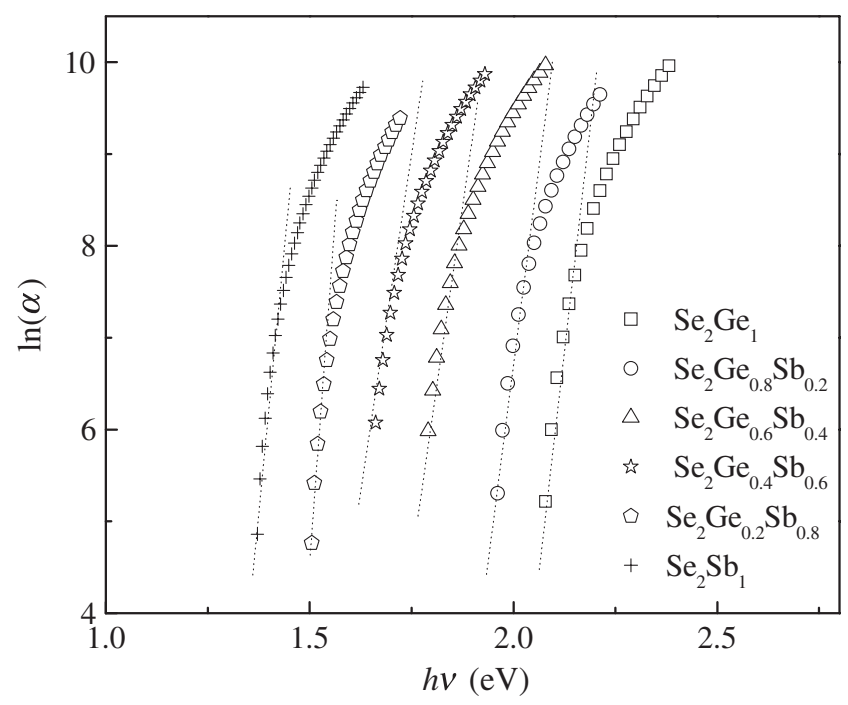

Figure 7. Exponential dependence of the absorption coefficient on the photon energy for $\mathrm{Ge}_{x} \mathrm{Se}_{2} \mathrm{Sb}_{1-x}$ thin films with $(0.0 \leq x \leq 1)$.

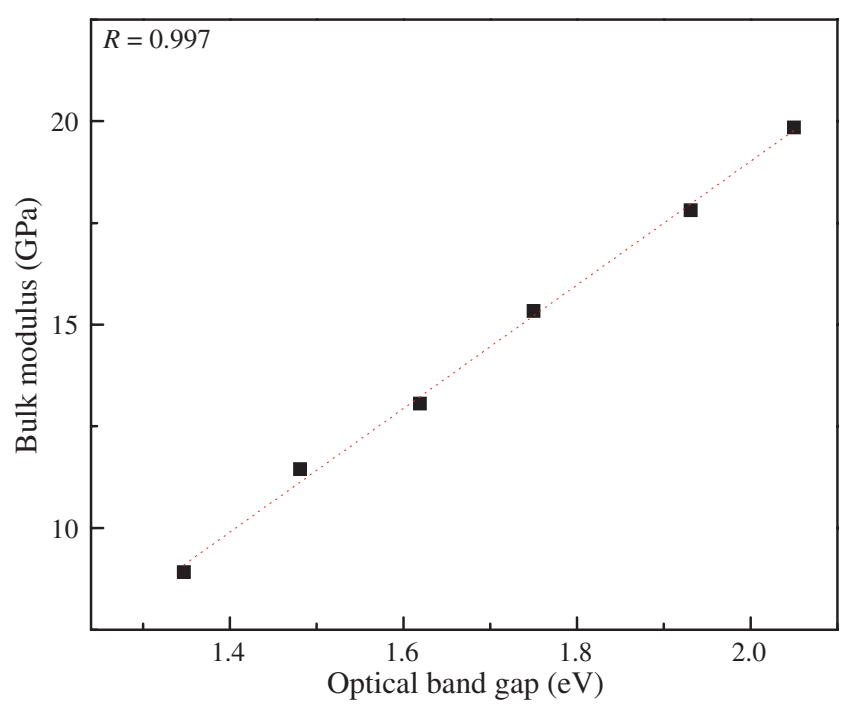

Figure 8. Values of the optical band gap $v s$. the bulk modulus for $\mathrm{Ge}_{x} \mathrm{Se}_{2} \mathrm{Sb}_{1-x}$ films with $(0.0 \leq x \leq 1)$.

where $M$ and $\rho$ are the molecular weight and density of the material, respectively, in terms the optical electronegativity as [44]

$$
\propto_{0}=0.395((4.207+k) /(7.207+k)) V_{\mathrm{m}},
$$

where $k=(\ln \Delta \chi)(\ln \Delta \chi-4.564)$ and in terms of the optical bang gap as [45]

$$
\begin{aligned}
\propto_{0}=0.395( & 12.41-\sqrt{E_{\mathrm{g}}-0.365} / 12.41 \\
& \left.+2 \sqrt{E_{\mathrm{g}}-0.365}\right) V_{\mathrm{m}}
\end{aligned}
$$

The deduced values of $\alpha_{0}$ based on the above equations (2) and (6)-(8) are very close to each other (table 3 ). In order to correlate the optical band gap and bulk modulus, figure 8 shows the plot of $E_{\mathrm{g}}$ values vs. $B$ for $\mathrm{Ge}_{x} \mathrm{Se}_{2} \mathrm{Sb}_{1-x}$ glassy films. This figure confirmed that there is a linear dependence between $E_{\mathrm{g}}$ and $B$ can be expressed as

$$
B_{\mathrm{th}}=15.2 E_{\mathrm{g}}-11.38 \text {. }
$$


The above equation satisfied for the glasses under study and it gave values of the bulk modules as well as those determined based on the ultrasonic velocities (see table 3 ). In other words, substituting the values of $B$ into equation (9) gives the values of the electronegativity or the optical gap for $\mathrm{Ge}_{x} \mathrm{Se}_{2} \mathrm{Sb}_{1-x}$ glasses and vice versa. Taking this in mind it was suggested that equation (3) by Aly [46] and also equation (2) in reference [42] are not satisfied for $\mathrm{Ge}_{x} \mathrm{Se}_{2} \mathrm{Sb}_{1-x}$ glasses.

\section{Conclusions}

In the present work different compositions of $\mathrm{Ge}_{x} \mathrm{Se}_{2} \mathrm{Sb}_{1-x}$ glasses were prepared in the form of bulk samples and thin films. The amorphous state of the as-prepared glasses and thin films were confirmed by the absence of any sharp lines or peaks in the XRD patterns. The effect of the addition of antimony onto GeSe glass on the elastic moduli and the optical properties was investigated. Increasing the concentration of $\mathrm{Sb}$ at the expense of $\mathrm{Ge}$ results in the

- Increase in the glass density $(\rho)$, molar volume $\left(V_{\mathrm{m}}\right)$ that ascribed to the lowest values of the atomic weight and density of $\mathrm{Sb}$ in comparison with that of Ge atoms.

- Increase the values of Poisson's ratio $(\sigma)$ that can be ascribed to the increase of defect homopolar Se-Se bonds and also by increasing $\mathrm{Sb}$ content the ordering degree of the amorphous species $\left(\mathrm{Se}_{2} \mathrm{Sb}_{3}\right)$ increases with slight ordering in the periodicity at the expense of the amorphous matrix that increasing the values of the density and decreasing the elastic moduli.

- Decrease the Debye temperature $\left(T_{\mathrm{D}}\right)$ was attributed to the decrease in ultrasonic velocities.

- A good correlation between the optical band gap $\left(E_{\mathrm{g}}\right)$, electronegativity $(\Delta \chi)$, and the bulk modulus has been found in these glasses under study.

- Decrease in the optical band gap $\left(E_{\mathrm{g}}\right)$ can be attributed to the increase in the Urbach tail slope $(\Gamma)$ and vice versa.

- Increase of the refractive index can be interpreted in terms of the increasing electronic polarizability with the increase in $\mathrm{Sb}$ content.

\section{Acknowledgement}

We wish to thank Physics Department, Al Azhar University, Assuit Branch, Egypt, for the financial support.

\section{References}

[1] Ohta T 2001 J. Optoelectron. Adv. Mater. 3609

[2] Aggarwal I D and Sanghera J S 2002 J. Optoelectron. Adv. Mater. 4665

[3] Kolobov A V and Tominaga J 2002 J. Optoelectron. Adv. Mater. 4679

[4] Lainé M and Seddon A B 1995 J. Non-Cryst. Solids 18430
[5] Shaaban E R, Yahia I S and Fadel M 2009 J. Alloys Compd. 469427

[6] Shaaban E R, Kaid M A, Moustafa E S and Adel A $2008 \mathrm{~J}$. Phys. D: Appl. Phys. 41125301

[7] Shaaban E R 2007 J. Phys. Chem. Solids 68400

[8] Singh S, Kumar S and Kumar A 2004 J. Optoelectron. Adv. Mater. 61153

[9] Choudhary N, Goyal D K and Kumar A 2004 J. Eng. Mater. Sci. 1155

[10] Rajagopalan T and Reddy G B 1999 Thin Solid Films 353254

[11] Mathur R and Kumar A 1986 Solid State Commun. 59163

[12] Toghe N, Minami T and Manaka M 1983 J. Non-Cryst. Solids 59-60999

[13] Shaaban E R 2008 Philos. Mag. 88781

[14] Shaaban E R, Dessouky M T and Abousehly A M 2008 Philos. Mag. 881099

[15] Aly K A and Abdel-Rahim F M 2013 J. Alloys Compd. 561 284

[16] Rabinal M K, Sangunni K S and Gopal E S R 1995 J. NonCryst. Solids $\mathbf{1 8 8} 98$

[17] Aly K A, Abousehly A M, Osman M A and Othman A A 2008 Phys. B: Condens. Matter 4031848

[18] Rajagopalan T and Reddy G B 1998 J. Mater. Sci.: Mater. Electron. 9133

[19] Swanepoel R 1983 J. Phys. E: Sci. Instrum. 161214

[20] Márquez E, Bernal-Oliva A M, González-Leal J M, PrietoAlcón R and Jiménez-Garay R 1997 J. Non-Cryst. Solids 222 250

[21] Rajendran V, Palanivelu N, Palanichamy P, Jayakumar T, Raj B and Chaudhuri B K 2001 J. Non-Cryst. Solids 29639

[22] Hilton A R, Hayes D J and Rechtin M D 1975 J. Non-Cryst. Solids 17319

[23] Bridge B, Patel N D and Waters D N 1983 Phys. Status Solidi (A): Appl. Res. 77655

[24] Khafagy A H, Abo-Ghazala M, El-Zaidia M M and Ammar A A 1991 J. Mater. Sci. 263477

[25] Elshafie A 1997 Mater. Chem. Phys. 51182

[26] Elshafie A 1996 J. Phys. D: Appl. Phys. 29991

[27] Ivanova Z G, Vassilev V S and Vassileva K G 1993 J. NonCryst. Solids 162123

[28] Lovas A, Kiss L F and Sommer F 1995 J. Non-Cryst. Solids 192-193 608

[29] Anderson O L 1963 J. Phys. Chem. Solids 24909

[30] El-Mallawany R, Sidkey M, Khafagy A and Afifi H 1994 Mater. Chem. Phys. 37295

[31] Bicerano J and Ovshinsky S R 1985 J. Non-Cryst. Solids 74 75

[32] Dahshan A and Aly K A 2015 J. Non-Cryst. Solids 40862

[33] Dahshan A and Aly K A 2008 Philos. Mag. 88361

[34] Mahadevan S, Giridhar A and Singh A K 1983 J. Non-Cryst. Solids $\mathbf{5 7} 423$

[35] Giridhar A, Narasimham P S L and Mahadevan S $1981 \mathrm{~J}$. Non-Cryst. Solids 43 29-35

[36] Gopal E S R, Mukundan T S, Philip J and Sathish S 1987 Pramana 28471

[37] Aly K A, Abd Elnaeim A M, Uosif M A M and Abdel-Rahim O 2011 Physica B: Condens. Matter 4064227 
[38] Aly K A 2010 Appl. Phys. A 99913

[39] Saddeek Y B and Aly K A 2014 Mater. Chem. Phys. 144 433

[40] Aly K A 2009 Philos. Mag. 891063

[41] Aly K A 2009 J. Non-Cryst. Solids 3551489

[42] Reddy R R, Nazeer Ahammed Y, Rama Gopal K, Abdul Azeem P, Rao T V R and Mallikarjuna Reddy P 2000 Opt. Mater. 14355
[43] Reddy R R, Nazeer Ahammed Y, Rama Gopal K and Rao T V R 1998 Infrared Phys. Technol. 3955

[44] Reddy R R, Nazeer Ahammed Y, Rama Gopal K, Abdul Azeem P, Raguram D V and Rao T V R 1999 J. Magn. Magn. Mater. 192516

[45] Reddy R R and Ahammed Y N 1996 Infrared Phys. Technol. 37505

[46] Aly K A 2015 J. Alloys Compd. 630178 